\title{
Altruistic Punishment and Impulsivity in Parkinson's Disease: A Social Neuroscience Perspective
}

\author{
Rosalba Morese ${ }^{1,2 * \dagger}$ and Sara Palermo ${ }^{3,4 \dagger}$ \\ ${ }^{1}$ Institute of Public Health, Faculty of Biomedical Sciences, Università della Svizzera italiana, Lugano, Switzerland, ${ }^{2}$ Faculty of \\ Communication, Culture and Society, Università della Svizzera italiana, Lugano, Switzerland, ${ }^{3}$ Center for the Study of \\ Movement Disorders, Department of Neuroscience, University of Turin, Turin, Italy, ${ }^{4}$ European Innovation Partnership on \\ Active and Healthy Ageing, Brussels, Belgium
}

\section{OPEN ACCESS}

Edited by:

Giuseppe Curcio,

University of L'Aquila, Italy

Reviewed by: Alexander Nikolaevich Savostyanov, State Scientific Research Institute of

Physiology and Basic Medicine,

Russia

Frauke Nees,

University of Heidelberg,

Germany

*Correspondence:

Rosalba Morese

rosalba.morese@usi.ch

tThese authors have contributed equally to this work

Specialty section:

This article was submitted to Individual and Social Behaviors, a section of the journal Frontiers in Behavioral Neuroscience

Received: 10 February 2020 Accepted: 25 May 2020 Published: 21 July 2020

Citation: Morese $R$ and Palermo $S$ (2020) Altruistic Punishment and Impulsivity in Parkinson's Disease: A Social Neuroscience Perspective. Front. Behav. Neurosci. 14:102. doi: 10.3389/fnbeh.2020.00102
Non-motor symptoms of Parkinson's disease (PD) are of increasing interest in clinical and psychological research. Disinhibition-the inability to inhibit inappropriate behavior - leads to social and emotional impairments, including impulsive behavior and disregard for social conventions and decision-making behavior. In recent years, the latter has been investigated using economic exchanges during social interactions. Altruistic punishment - to punish someone who violates group norms even if it foresees a personal cost - is one of the most useful and fruitful paradigms; it allows to maintain a cooperation system within social groups. Alterations of this cognitive ability negatively impact the quality of life of the individual and social stability. Social neuroscience has suggested association between impulsive behaviors and altruistic punishment. Neuroimaging research aimed at exploring functional networks and intrinsic functional connectivity went in this direction. To date, little is known about these issues in neurodegenerative diseases such as PD. Dopamine replacement treatment and dopamine-agonists have been associated with impulse-control disorder and impulsive-compulsive behavior able to affect social decision-making. Frontal-executive dysfunction determines an alteration of social functioning through a mechanism of subversion of online action-monitoring, which associates disinhibition with volition. Genetic polymorphisms, alterations of the nigro-striatal substance, and impairment in the medial prefrontal cortex and in the Default mode network (DMN) seem to be able to explain these mechanisms. This theoretical perspective article aims to present these topics in order to encourage an interdisciplinary discussion capable of generating new research and developing rehabilitative intervention to improve social decision-making in PD patients.

Keywords: impulsive behavior, altruistic punishment, Parkinson's disease, social cognition, social norms, ingroup and outgroup contexts, default mode network (DMN), functional magnetic resonance imaging (fMRI)

\section{INTRODUCTION}

This theoretical paper aims to suggest an interdisciplinary vision in Parkinson's disease (PD) research among different disciplines. Non-motor symptoms in PD are increasingly capturing attention from interdisciplinary research in which psychology, neuroscience, and clinical medicine converge. During the last decades, neuroscientific studies investigated mental processes 
activated during resting state and social scenarios using economic games (see Sanfey et al., 2006). Theories and experimental paradigms developed by social neurosciences are useful for better understanding impulsivity and decision-making in social situations such as in altruistic punishment, to punish someone who violates group norms even if it foresees a personal cost.

To date, very few studies investigated altruistic punishment in motor neurodegenerative diseases, such as PD. The present theoretical perspective article focuses on common points between impulsivity, metacognitive-executive functions, decision-making processes, and neurobiological factors potentially involved in altruistic punishment in PD patients.

\section{ALTRUISTIC PUNISHMENT}

Social behaviors arise from "cooperation" which represents a distinctive ability of human beings: that is, the process of individuals and groups acting for their mutual benefit. Cooperation played an important role in the evolution of human social life, allowing the organization in social groups through the creation of social norms (Fehr and Schmidt, 1999; Fehr and Gächter, 2000, 2002; Tomasello, 2009; Boyd et al., 2010; Morese et al., 2018). Joining social groups, respecting their own social norms, has ensured a greater survival in evolutionary history compared to a life in solitude and isolation. Therefore, the transgression has always been sanctioned.

The altruistic punishment behavior-to punish someone has carried out an unfair behavior at one's own cost and with no personal benefit-has been widely studied across several cultures (Fehr and Gächter, 2000, 2002; Gardner and West, 2004; Raihani et al., 2012; Balafoutas et al., 2016; Morese et al., 2016; Rabellino et al., 2016). Djamshidian et al. (2011) underlined how it may have the function of breaking down the amount of unfair behavior within the group. Several authors suggested how altruistic punishment represents the basic nature of cooperation: i.e., cooperation and punishment co-evolve as the one who punishes unfair behavior is considered more reliable, being therefore rewarded for his/her cooperation by the other members of the group (Fehr and Gächter, 2000, 2002; Fehr and Fischbacher, 2004; Gao et al., 2015; Grimalda et al., 2016; Greenwood et al., 2018; Huang et al., 2018). Morese (2018), in line with Henrich et al. (2005), highlights how altruistic punishment is opposed to the classic vision of homo economicus guided only by rationality and utilitarian decisions.

Considering the above, altruistic punishment would support emotional processes during social decision-making. Socially driven emotions can be successfully modulated by reappraisal strategies that focus on the reinterpretation of others' intentions. Indeed, emotion regulation plays a key role in altruistic punishment behavior. According to the theoretical model proposed by Fehr and Gächter (2000, 2002), the altruistic punishment behavior is exercised within the social group and it guarantees the maintenance of cooperation between the members. The experimental paradigm used for the study of altruistic punishment is the Third-Party Punishment (TPP). In this game, a player observes an economic interaction between two other players. One of them can decide to share part of his or her money with the other player, who can only passively accept his or her choice. The player observing the exchange of money can decide whether to punish the behavior if deemed unfair (Morese et al., 2016).

In the last decade, there has been an increasing interest in these issues, while great developments have taken place, thanks to functional neuroimaging techniques (de Quervain et al., 2004; Buckholtz and Marois, 2012; Yang et al., 2019; Zinchenko, 2019).

\section{ALTRUISTIC PUNISHMENT AND REWARD SYSTEM}

The altruist punishment behavior appears to have its neural substrate in the reward system. The reward system is a group of neural structures responsible for motivation, associative learning, and positive emotions, especially those involving pleasure as a fundamental component. The thalamus, dorsolateral prefrontal cortex (DLPFC), nucleus accumbens, anterior cingulate cortex (ACC), insula, and caudate nucleus are considered to be part of this neural system (Sanfey et al., 2003; de Quervain et al., 2004; King-Casas et al., 2005; Strobel et al., 2011; Buckholtz and Marois, 2012; Morese et al., 2016; Zinchenko, 2019).

Haber et al. (2006) highlighted the mediation of DLPFC and caudate in punishment responses, being these hubs involved in directing attention toward relevant stimuli, or in understanding communication intentions between individuals. Strobel et al. (2011) discovered that observing unfair behavior evokes the recruitment of the anterior insula-usually activated in the process of disgust-and, therefore, they associated disgust with violation of social norms. Other authors suggested an involvement in brain area usually activated during Theory of Mind (ToM) tasks, such as the medial prefrontal cortex (MPFC) and the temporal-parietal junction (TPJ; Baumgartner et al., 2012; Lo Gerfo et al., 2019). Buckholtz and Marois (2012) proposed the DLPFC, the posterior parietal cortex (PPC), and functional connectivity network [such as the central executive network (CEN)] as involved in decisionmaking during economic tasks aimed at assigning adequate punishments. More recently, Morese et al. (2016) found the recruitment of the ventral tegmental area (VTA), the MPFC, caudate, and cingulate cortex during tasks eliciting altruistic punishment behavior. VTA plays a central role in the production of dopamine, a neurotransmitter produced in motivation and reward behaviors.

The dopaminergic reward system and VTA are vulnerable in $\mathrm{PD}$, and reward processing abnormalities have been previously identified (Kapogiannis et al., 2011). This might suggest potential altruistic punishment disabilities which must be investigated through a neurocognitive approach (Palermo et al., 2019).

\section{PARKINSON'S DISEASE, IMPULSIVITY, AND SOCIAL DECISION-MAKING}

$\mathrm{PD}$ is a progressive neurodegenerative disorder that affects the central and peripheral nervous systems. Specifically, the depletion of dopaminergic neurons affects the functioning 
of four fronto-striatal circuits involved in different motor, cognitive, affective, and motivational aspects of behavior (the supplementary motor area, the dorsolateral prefrontal, the orbitofrontal, and the anterior cingulate loops; Palermo et al., 2017a,b, 2018a, 2019; Palermo and Morese, 2018).

Rest tremor, bradykinesia, rigidity, and loss of postural reflexes are generally considered the cardinal signs of PD. Other clinical features include secondary motor symptoms (such as dysarthria, dysphagia, dystonia, festination, freezing, glabellar reflexes, hypomimia, micrographia, shuffling gait, sialorrhoea) and non-motor symptoms (such as autonomic dysfunction, behavioral aberrations, cognitive dysfunctions, sensory abnormalities, and sleep disorders; Jankovic, 2008; Chaudhuri et al., 2011; Palermo et al., 2019). Non-motor symptoms can be more disabling and resistant to treatment than cardinal signs and are key determinants of quality of life in PD (Chaudhuri et al., 2011; Palermo et al., 2019).

As is known, the fundamental therapy for PD is still the pharmacological one, which is implemented with the administration of various active ingredients in addition to levodopa, which remains the most powerful medication, but which presents marked side effects after a few years (Romagnolo et al., 2018; Palermo et al., 2019).

For example, dopamine replacement treatment and dopamine-agonists have been associated with impulse-control disorder, since they can induce changes in those fronto-striatal networks that manage reward and mediate impulse monitoring and control (Ray and Strafella, 2010; Djamshidian et al., 2011). Indeed, tonic stimulation of dopamine receptors damages inhibitory control mechanisms and reward processing while promoting compulsive repetition of behavior (Ray and Strafella, 2010). Impulse-control disorders are associated with appetite disturbance, mood deflection, disinhibition, and irritability (Pontone et al., 2006). Moreover, dysfunction in mental processing speed, shifting between different conceptual sets, and response-inhibition are often encountered, suggesting frontal-executive dysfunction (Palermo et al., 2017a; Palermo and Morese, 2018). All these factors determine an alteration of social functioning through a mechanism of subversion of online action-monitoring, which associates disinhibition with volition. All these factors determine an alteration of social functioning through a mechanism of subversion of online actionmonitoring, which associates disinhibition with volition [e.g., pathological gambling; National Research Council (US), 1999; Marazziti et al., 2014].

Disinhibition is habitually considered a synonym for impulsivity (Kocka and Gagnon, 2014). While disinhibition is the background on which euphoria, impulsiveness, and inadequate emotional actions are superimposed (Luria, 1969), impulsivity alters decision-making and motor control in terms of response inhibition (Napier et al., 2015; Palermo and Morese, 2018). A fronto-striatal and cingulo-frontal dysfunction may reflect impairment in metacognitive-executive abilities (such as actionmonitoring, response-inhibition, and error awareness; Morese et al., 2018; Palermo et al., 2018b) and promote compulsive repetition of behavior (Palermo et al., 2017a), such as in the case of pathological gambling.
Voon et al. (2011) pointed out an enriched bottom-up ventral-striatal dopamine release to incentive cues, gambling tasks and reward prediction, and possible inhibition of top-down orbito-frontal influences. Thus, dopamine agonist-related ventral-striatal hypo-functionality entails with pounding, medication abuse, hoarding, kleptomania, compulsive shopping, hypersexuality, compulsive eating, and pathological gambling (Voon et al., 2011). Dopaminergic (dys)regulation in PD patients with pathological and non-pathological gambling experience has been previously studied using positron emission tomography (Steeves et al., 2009). Neuroimaging findings suggested that patients with pathological gambling exhibit a substantial reduction in the ventral striatum compared to normal controls. The ventral striatum communicates with the limbic and cortical brain structures, being implicated in core regulatory functions such as for motor-like and rewardrelated behaviors (Steeves et al., 2009). Importantly, Crockett et al. (2010) investigated the relationship among impulsive choice, reward system, and altruistic punishment in economic games, focusing on the role of serotonin. Authors found that a reduction in serotonin levels increased impulsive choice and altruistic punishment behavior. Importantly, the examination of dopamine/glutamate receptors and serotonin transporter gene polymorphisms recognized D3 dopamine receptor p.S9G and GRIN2B c.366C $>\mathrm{G}$ as a risk factor for impulse-control disorders in PD (Lee et al., 2009). Genetic polymorphisms may contribute to impulsivity susceptibility (Lee et al., 2009), while modulating social value processing in the striatum, producing context-dependent effects on social decision-making and behavior (Crockett et al., 2013).

\section{ALTRUISTIC PUNISHMENT AND PARKINSON'S DISEASE}

Although dopaminergic dysregulation and its repercussions on social decision-making and behavior are well known, neuroimaging studies evaluating altruistic punishment behavior have not been carried out on PD patients. To date, only the study by Djamshidian et al. (2011) investigates altruistic punishment in PD patients with and without impulsivecompulsive behaviors (ICBs) and healthy participants. Authors adopted an experimental task used based on the research by de Quervain et al. (2004): a trust economic game during which participants must decide whether to punish the fair/unfair behavior of other players. The experimental procedure was simulated through an internet connection so that all participants believed they were "actually" playing with other players. Eight participants played with one trustee per round. In the beginning, each participant received a real sum of $£ 10$ which they could decide to give to another player or not. The sum was then quadrupled in each round, and the single player could decide whether to return a portion of the investment to the other participants. At the end, players received $£ 10$ more with the option of punishing the other participants but with the clause that the punisher loses $£ 1$ for every $£ 2$ used to punish. The authors found that PD patients with ICBs punished more than controls on medication, but like controls 


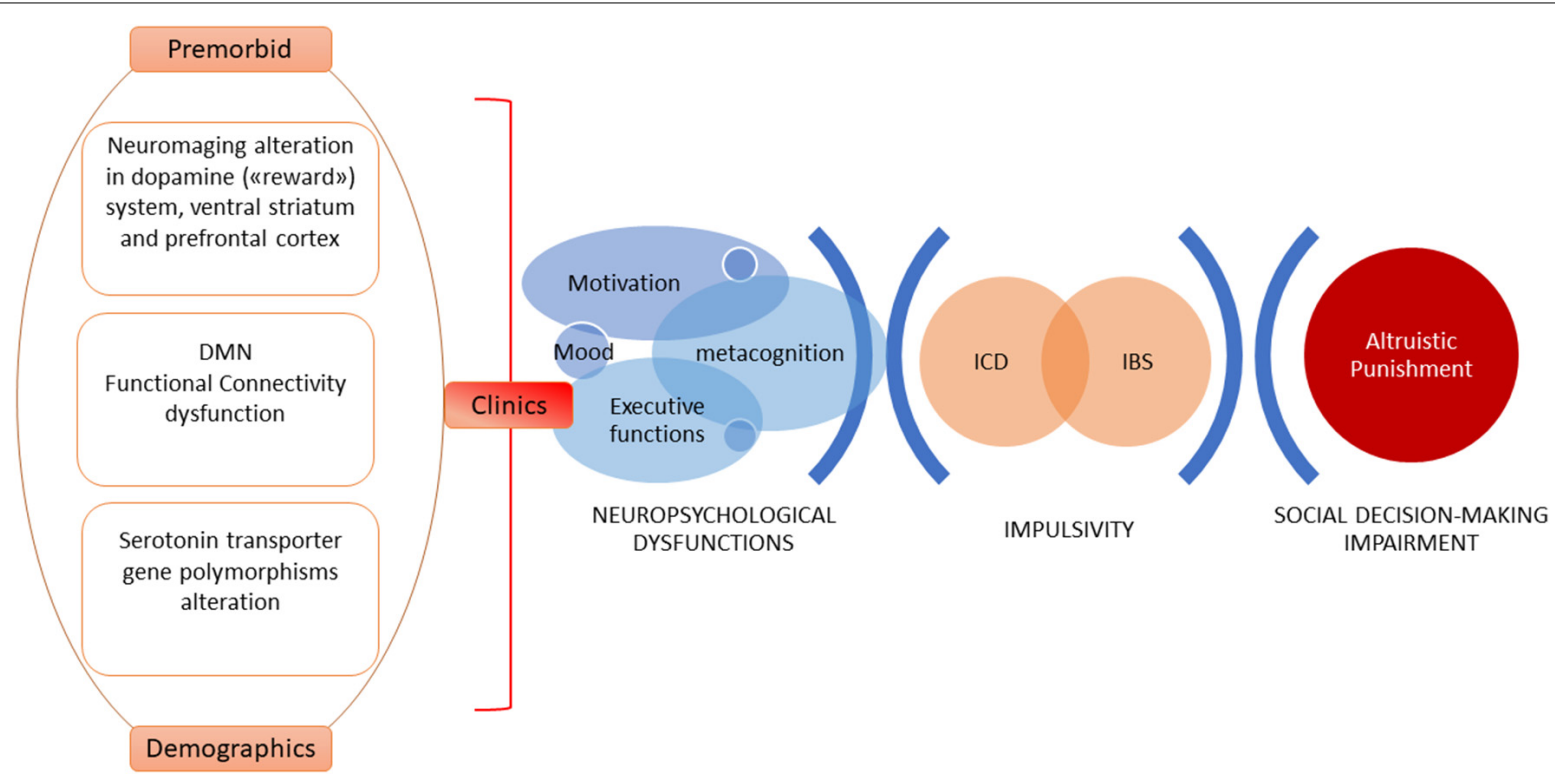

FIGURE 1 | A model of explanation of altruistic punishment impairment in Parkinson's disease (PD). Complex and widespread cognitive skills such as those related to social cognition require a multidimensional approach. Clinical and demographic predictors, neurobiological and psychobiological factors, and changes in the cognitive-behavioral domain are able to explain impulsive control behaviors characterized by anomalies in reward-driven actions, inhibitory control dysfunctions, and online-monitoring difficulties. These elements - in turn-affect social decision-making, altering the mechanism of altruistic punishment.

off medication. These results suggest a role for dopamine in altruistic punishment decisions in PD patients with ICBs (Djamshidian et al., 2011). Indeed, dopaminergic medication can accentuate the desire to enforce social and cooperation rules even if impulsiveness is considered unsuitable for adherence to the group (Djamshidian et al., 2011).

Theoretical models explaining altruistic punishment behavior focus on the motivation to punish, trying to discern if it results from a motivational cooperative drive or emotions, such as negative ones (Fehr and Gächter, 2002; Rodrigues et al., 2018). Rodrigues et al. (2018) demonstrated that altruistic punishment can hide negative emotion (anger)-which could be considered as a cover motivational factor. Importantly, PD patients with ICBs can become quite aggressive and have reduced/inexistent self-awareness that their behaviors are unacceptable to others (Djamshidian et al., 2011). Considering the above, new neuroimaging studies on PD patients will have to be designed to explore altruistic punishment neural underpinnings and to discriminate which cover emotions could be able to predict altruistic punishment behavior (see Figure 1).

\section{DEFAULT MODE NETWORK AND ALTRUISTIC PUNISHMENT IN PARKINSON'S DISEASE}

The default mode network (DMN) is a neural network distributed in different cortical and subcortical regions, which is generally activated during hours of rest and "passive" activities (intrinsic functional connectivity). The cortical and subcortical structures that are part of this resting state network can partly vary from individual to individual, but in general, they are attributable to some main brain areas: the posterior cingulate cortex (PCC), the MPFC, the precuneus, the medial temporal lobe (MTL) and the inferior parietal cortex (IPC), and the ACC (Lucas-Jiménez et al., 2016).

The cognitive skills related to the DMN activation concern are as follows: ability to access memories of one's life (autobiographical episodic memory), to reflect on one's own and others' mental states, to recognize familiar/non-familiar stimuli, and to experience emotions in relation to social situations that concern ourselves or others, to evaluate our own and others' reactions in some emotional situations. DMN has been found to have a key role also in Third-Party Punishment (TPP), which is explained in a review by Krueger and Hoffman (2016). The authors described the role of three resting state networks elicited during TPP: (1) the salience network (SN), which detects and generates an aversive experience that initiates TPP; (2) the DMN, which integrates the perceived harm and inference of intentions into an assessment of blame; and (3) the CEN, which converts the blame signal into a specific punishment decision.

As explained by Zinchenko and Klucharev (2017), to understand the neural mechanisms of TPP, it is crucial to clarify the neurocomputational mechanism that allows the TPJ (as a part of the DMN) to link norm-violation detection ( $\mathrm{SN}$ ) to specific punishments (CEN).

The association between DMN and the neural basis of social cognition has long been known (Schilbach et al., 2008; Reniers et al., 2012). Hagmann et al. (2008) identified in the TPJ and MFC (as part of the DMN) activations linked to ToM, the ability to attribute mental states-beliefs, intentions, desires, emotions, knowledge-to oneself and to others, and the ability 
to understand that others have different mental states from their own. In particular, Reniers et al. (2012) reported increased activity in the brain area associated with the DMN during moral decision-making and reduced activation in the DLPFC, when subjecting healthy volunteers to ToM tasks.

PD patients exhibit executive dysfunctions (van Eimeren et al., 2009; Amanzio et al., 2014; Palermo et al., 2017a, 2018a) and ToM disabilities (Palermo et al., 2017a) that are able to explain difficulties in social cognition. Importantly, van Eimeren et al. (2009) supposed a specific DMN malfunctioning during an executive task in PD plausibly linked to dopamine depletion. More recently, Wolters et al. (2019) discussed reduced connectivity in networks related to cognitive impairment and, potentially, affecting social behavior. They found that the DMN was the most prominently involved.

\section{CONCLUSIONS}

To understand PD non-motor symptoms, we can allow a multidimensional and personalized approach to patients aimed at enhancing the quality of life (Morese et al., 2018). ICBs-in terms of response-inhibition-has been widely studied applying functional magnetic resonance imaging (fMRI) Go/NoGo paradigm (Braver et al., 2001; Palermo et al., 2018a,b; Gao et al., 2019). This represents a classic experimental design in which a different response frequency is created between responding and not responding to the stimulus (Palermo et al., 2017a,b, 2018b). The conflict is created by the competition between the Go response and the NoGo inhibition response recruiting online monitoring and executive control processes. The fronto-striatal dysfunctions derived by ACC, DPFC, and MPFC hypo-functionality explain executive dysfunction-related to action-monitoring, response-inhibition,

\section{REFERENCES}

Amanzio, M., Palermo, S., Zibetti, M., Leotta, D., Rosato, R., Geminiani, G., et al. (2014). Self-unawareness of levodopa induced dyskinesias in patients with Parkinson's disease. Brain Cogn. 90, 135-141. doi: 10.1016/j.bandc.2014. 06.014

Atmaca, M. (2014). Drug-induced impulse control disorders: a review. Curr. Clin. Pharmacol. 9, 70-74. doi: 10.2174/1574884708666131111202954

Balafoutas, L., Nikiforakis, N., and Rockenbach, B. (2016). Altruistic punishment does not increase with the severity of norm violations in the field. Nat. Commun. 7:13327. doi: 10.1038/ncomms13327

Baumgartner, T., Götte, L., Gügler, R., and Fehr, E. (2012). The mentalizing network orchestrates the impact of parochial altruism on social norm enforcement. Hum. Brain Mapp. 33, 1452-1469. doi: 10.1002/hbm.21298

Boyd, R., Gintis, H., and Bowles, S. (2010). Coordinated punishment of defectors sustains cooperation and can proliferate when rare. Science 328, 617-620. doi: 10.1126/science.1183665

Braver, T. S., Barch, D. M., Gray, J. R., Molfese, D. L., and Snyder, A. (2001). Anterior cingulate cortex and response conflict: effects of frequency, inhibition and errors. Cereb. Cortex 11, 825-836. doi: 10.1093/cercor/11.9.825

Buckholtz, J. W., and Marois, R. (2012). The roots of modern justice: cognitive and neural foundations of social norms and their enforcement. Nat. Neurosci. 15, 655-661. doi: 10.1038/nn.3087

Chaudhuri, K. R., Odin, P., Antonini, A., and Martinez-Martin, P. (2011). Parkinson's disease: the non-motor issues. Parkinsonism Relat. Disord. 17, 717-723. doi: 10.1016/j.parkreldis.2011.02.018 and disinhibition responses (Palermo et al., 2017a,b; Palermo and Morese, 2018), which are able to explain also social behavior. Specifically, dysfunctions in these brain areas contribute to impulsivity in PD and metacognitive-executive dysfunctions, potentially involved in altruistic punishment and social decisionmaking. These evidences have been confirmed not only by fMRI-based paradigm but also by research on resting state networks such as DMN (Schilbach et al., 2008; Reniers et al., 2012; Wolters et al., 2019).

Interdisciplinary perspective could deepen the neurophysiological mechanisms underlying the difficulties in daily life in PD patients. Impulse-control disorders and ICBs can become harmful for PD patients and caregivers, affecting quality of life and social engagement within the contexts of the social groups they belong to Atmaca (2014). We proposed to invest in new frontier bridges between disciplines which will be able to promote new investigation on social cognition in PD. One of the hot topics will certainly be understanding how metacognitive-executive functions and social abilities influence altruistic punishment and TPP in PD.

\section{AUTHOR CONTRIBUTIONS}

$\mathrm{RM}$ conceived the content of the article, wrote the first draft, and reviewed the manuscript. SP wrote the second version of the manuscript, produced infographics, and supervised revision and critiques.

\section{FUNDING}

This research was supported by PRIN 2015 PER-FORMARE IL SOCIALE. Formazione, cura e inclusione sociale attraverso il teatro, principal investigator (PI) Prof. Bernardi.

Crockett, M. J., Apergis-Schoute, A., Herrmann, B., Lieberman, M. D., Müller, U., Robbins, T. W., et al. (2013). Serotonin modulates striatal responses to fairness and retaliation in humans. J. Neurosci. 33, 3505-3513. doi: 10.1523/JNEUROSCI.0944-13.2013

Crockett, M. J., Clark, L., Lieberman, M. D., Tabibnia, G., and Robbins, T. W. (2010). Impulsive choice and altruistic punishment are correlated and increase in tandem with serotonin depletion. Emotion 10, 855-862. doi: $10.1037 / \mathrm{a} 0019861$

de Quervain, D. J., Fischbacher, U., Treyer, V., Schellhammer, M., Schnyder, U., Buck, A., et al. (2004). The neural basis of altruistic punishment. Science 305, 1254-1258. doi: 10.1126/science.1100735

Djamshidian, A., O’Sullivan, S. S., Doherty, K., Lees, A. J., and Averbeck, B. B. (2011). Altruistic punishment in patients with Parkinson's disease with and without impulsive behaviour. Neuropsychologia 49, 103-107. doi: 10.1016/j. neuropsychologia.2010.10.012

Fehr, E., and Fischbacher, U. (2004). Third-party punishment and social norms. Evol. Hum. Behav. 25, 63-87. doi: 10.1016/s1090-5138(04)00005-4

Fehr, E., and Gächter, S. (2000). Cooperation and punishment in public goods experiments. Am. Econ. Rev. 90, 980-994. doi: 10.1257/aer.90.4.980

Fehr, E., and Gächter, S. (2002). Altruistic punishment in humans. Nature 415, 137-140. doi: 10.1038/415137a

Fehr, E., and Schmidt, K. M. (1999). A theory of fairness, competition and cooperation. Q. J. Econ. 114, 817-868. doi: 10.1162/003355399556151

Gao, L., Wang, Z., Pansini, R., Li, Y. T., and Wang, R. W. (2015). Collective punishment is more effective than collective reward for promoting cooperation. Sci. Rep. 5:17752. doi: 10.1038/srep17752 
Gao, Q., Jia, G., Zhao, J., and Zhang, D. (2019). Inhibitory control in excessive social networking users: evidence from an event-related potentialbased go-nogo task. Front. Psychol. 10:1810. doi: 10.3389/fpsyg.2019. 01810

Gardner, A., and West, S. A. (2004). Cooperation and punishment, especially in humans. Am. Nat. 164, 753-764. doi: 10.1086/425623

Greenwood, G. W., Abbass, H. A., and Petraki, E. (2018). When is altruistic punishment useful in social dilemmas? Biosystems 174, 60-62. doi: 10.1016/j. biosystems.2018.10.015

Grimalda, G., Pondorfer, A., and Tracer, D. P. (2016). Social image concerns promote cooperation more than altruistic punishment. Nat. Commun. 7:12288. doi: $10.1038 /$ ncomms 12288

Haber, S. N., Kim, K. S., Mailly, P., and Calzavara, R. (2006). Reward-related cortical inputs define a large striatal region in primates that interface with associative cortical connections, providing a substrate for incentive-based learning. J. Neurosci. 26, 8368-8376. doi: 10.1523/JNEUROSCI.0271-06.2006

Hagmann, P., Cammoun, L., Gigandet, X., Meuli, R., Honey, C. J., Wedeen, V. J., et al. (2008). Mapping the structural core of the human cerebral cortex. PLoS Biol 6:e159. doi: 10.1371/journal.pbio.0060159

Henrich, J., Boyd, R., Bowles, S., Camerer, C., Fehr, E., Gintis, H., et al. (2005). "Economic man" in cross-cultural perspective: behavioral experiments in 15 small-scale societies. Behav. Brain Sci. 28, 795-855. doi: $10.1017 / \mathrm{s} 0140525 \mathrm{x} 05000142$

Huang, F., Chen, X., and Wang, L. (2018). Evolution of cooperation in a hierarchical society with corruption control. J. Theor. Biol. 449, 60-72. doi: 10.1016/j.jtbi.2018.04.018

Jankovic, J. (2008). Parkinson's disease: clinical features and diagnosis. J. Neurol. Neurosurg. Psychiatry 79, 368-376. doi: 10.1136/jnnp.2007.131045

Kapogiannis, D., Mooshagian, E., Campion, P., Grafman, J., Zimmermann, T. J., Ladt, K. C., et al. (2011). Reward processing abnormalities in Parkinson's disease. Mov. Disord. 26, 1451-1457. doi: 10.1002/mds.23701

King-Casas, B., Tomlin, D., Anen, C., Camerer, C. F., Quartz, S. R., and Montague, P. R. (2005). Getting to know you: reputation and trust in a two-person economic exchange. Science 308, 78-83. doi: 10.1126/science. 1108062

Kocka, A., and Gagnon, J. (2014). Definition of impulsivity and related terms following traumatic brain injury: a review of the different concepts and measures used to assess impulsivity, disinhibition and other related concepts. Behav. Sci. 4, 352-370. doi: 10.3390/bs4040352

Krueger, F., and Hoffman, M. (2016). The emerging neuroscience of thirdparty punishment. Trends Neurosci. 39, 499-501. doi: 10.1016/j.tins.2016. 06.004

Lee, J. Y., Lee, E. K., Park, S. S., Lim, J.-Y., Kim, H. J., Kim, J. S., et al. (2009). Association of DRD3 and GRIN2B with impulse control and related behaviors in Parkinson's disease. Mov. Disord. 24, 1803-1810. doi: 10.1002/mds. 22678

Lo Gerfo, E., Gallucci, A., Morese, R., Vergallito, A., Ottone, S., Ponzano, F., et al. (2019). The role of ventromedial prefrontal cortex and temporo-parietal junction in third-party punishment behavior. NeuroImage 200, 501-510. doi: 10.1016/j.neuroimage.2019.06.047

Lucas-Jiménez, O., Ojeda, N., Peña, J., Díez-Cirarda, M., Cabrera-Zubizarreta, A., Gómez-Esteban, J. C., et al. (2016). Altered functional connectivity in the default mode network is associated with cognitive impairment and brain anatomical changes in Parkinson's disease. Parkinsonism Relat. Disord. 33, 58-64. doi: 10.1016/j.parkreldis.2016.09.012

Luria, A. R. (1969). "Frontal lobe syndromes," in Handbook of Clinical Neurology, vol. 2: Localization in Clinical Neurology, eds P. I. Vinken and G. W. Bruyns (Amsterdam: North-Holland), 725-757.

Marazziti, D., Picchetti, M., Baroni, S., Consoli, G., Ceresoli, D., Massimetti, G., et al. (2014). Pathological gambling and impulsivity: an Italian study. Riv. Psichiatr. 49, 95-99. doi: 10.1708/1461.16149

Morese, R. (2018). La punizione e la cooperazione in contesti di ingroup e outgroup. Riv. Internaz. Filosof. Psicol. 9, 286-301. doi: 10.4453/rifp.2018.0028

Morese, R., Mario, S., and Palermo, S. (2018). Commentary: metacognition and perspective-taking in Alzheimer's disease: a mini-review. Front. Psychol. 9:2010. doi: 10.3389/fpsyg.2018.02010

Morese, R., Rabellino, D., Sambataro, F., Perussia, F., Valentini, M. C., Bara, B. G., et al. (2016). Group membership modulates the neural circuitry underlying third party punishment. PLoS One 11:e0166357. doi: 10.1371/journal.pone. 0166357

Napier, T. C., Corvol, J. C., Grace, A. A., Roitman, J. D., Rowe, J., Voon, V., et al. (2015). Linking neuroscience with modern concepts of impulse control disorders in Parkinson's disease. Mov. Disord. 30, 141-149. doi: 10.1002/mds. 26068

National Research Council (US). (1999). Committee on the Social and Economic Impact of Pathological Gambling. Pathological Gambling: A Critical Review. Washington, DC: National Academies Press (US).

Palermo, S., Lopiano, L., Zibetti, M., Rosato, R., Leotta, D., and Amanzio, M. (2017a). A novel framework for understanding reduced awareness of dyskinesias in Parkinson's disease. Parkinsonism Relat. Disord. 39, 58-63. doi: 10.1016/j.parkreldis.2017.03.009

Palermo, S., Morese, R., Zibetti, M., Dematteis, F., Sirgiovanni, S., Stanziano, M., et al. (2017b). Impulse control disorder and response-inhibition alterations in Parkinson's disease. A rare case of totally absent functionality of the medial-prefrontal cortex and review of literature. J. Adv. Res. 8, 713-716. doi: 10.1016/j.jare.2017.09.004

Palermo, S., and Morese, R. (2018). "Disinhibition, response-inhibition and impulse control disorder in Parkinson's disease," in Horizons in Neuroscience Research, Vol. 35, eds A. Costa and E. Villalba (Happauge, NY: Nova Science Publisher), 135-164.

Palermo, S., Morese, R., Artusi, C. A., Stanziano, M., and Romagnolo, A. (2019). "Levodopa-induced dyskinesias and dyskinesias-reduced-self-awareness," in Parkinson's Disease: A Neurocognitive Approach, Parkinson's Disease and Beyond-A Neurocognitive Approach, eds S. Palermo, R. Morese, and M. Stanziano (London, UK: IntechOpen). doi: 10.5772/intechopen. 86384

Palermo, S., Lopiano, L., Morese, R., Zibetti, M., Romagnolo, A., Stanziano, M., et al. (2018a). Role of the cingulate cortex in dyskinesias-reduced-selfawareness: an fMRI study on Parkinson's disease patients. Front. Psychol. 9:1765. doi: 10.3389/fpsyg.2018.01765

Palermo, S., Stanziano, M., and Morese, R. (2018b). Commentary: anterior cingulate cortex and response conflict: effects of frequency, inhibition and errors. Front. Behav. Neurosci. 12:171. doi: 10.3389/fnbeh.2018.00171

Pontone, G., Williams, J. R., Bassett, S. S., and Marsh, L. (2006). Clinical features associated with impulse control disorders in Parkinson disease. Neurology 67, 1258-1261. doi: 10.1212/01.wnl.0000238401.76928.45

Rabellino, D., Morese, R., Ciaramidaro, A., Bara, B., and Bosco, F. M. (2016). Third-party punishment: altruistic and anti-social behaviours in in-group and out-group settings. J. Cogn. Psychol. 4, 486-495. doi: 10.1080/20445911.2016. 1138961

Raihani, N. J., Thornton, A., and Bshary, R. (2012). Punishment and cooperation in nature. Trends Ecol. Evol. 27, 288-295. doi: 10.1016/j.tree.2011. 12.004

Ray, N., and Strafella, A. P. (2010). Dopamine, reward, and frontostriatal circuitry in impulse control disorders in Parkinson's disease: insights from functional imaging. Clin. EEG Neurosci. 41, 87-93. doi: 10.1177/1550059410041 00208

Reniers, R. L., Corcoran, R., Völlm, B. A., Mashru, A., Howard, R., and Liddle, P. F. (2012). Moral decision-making, ToM, empathy and the default mode network. Biol. Psychol. 90, 202-210. doi: 10.1016/j.biopsycho.2012. 03.009

Rodrigues, J., Nagowski, N., Mussel, P., and Hewig, J. (2018). Altruistic punishment is connected to trait anger, not trait altruism, if compensation is available. Heliyon 4:e00962. doi: 10.1016/j.heliyon.2018.e00962

Romagnolo, A., Fabbri, M., Merola, A., Montanaro, E., Palermo, S., Martone, T., et al. (2018). Beyond 35 years of Parkinson's disease: a comprehensive clinical and instrumental assessment. J. Neurol. 265, 1989-1997. doi: 10.1007/s00415018-8955-Z

Sanfey, A. G., Loewenstein, G., McClure, S. M., and Cohen, J. D. (2006). Neuroeconomics: cross-currents in research on decision-making. Trends Cogn. Sci. 10, 108-116. doi: 10.1016/j.tics.2006.01.009

Sanfey, A. G., Rilling, J. K., Aronson, J. A., Nystrom, L. E., and Cohen, J. D. (2003). The neural basis of economic decision-making in the Ultimatum Game. Science 300, 1755-1758. doi: 10.1126/science.1082976

Schilbach, L., Eickhoff, S. B., Rotarska-Jagiela, A., Fink, G. R., and Vogeley, K. (2008). Minds at rest? Social cognition as the default mode of cognizing and 
its putative relationship to the "default system" of the brain. Conscious. Cogn. 17, 457-467.doi: 10.1016/j.concog.2008.03.013

Steeves, T. D., Miyasaki, J., Zurowski, M., Lang, A. E., Pellecchia, G., Van Eimeren, T., et al. (2009). Increased striatal dopamine release in Parkinsonian patients with pathological gambling: a [11C] raclopride PET study. Brain 132, 1376-1385. doi: 10.1093/brain/ awp054

Strobel, A., Zimmermann, J., Schmitz, A., Reuter, M., Lis, S., Windmann, S., et al. (2011). Beyond revenge: neural and genetic bases of altruistic punishment. NeuroImage 54, 671-680. doi: 10.1016/j.neuroimage.2010. 07.051

Tomasello, M. (2009). Why We Cooperate. Cambridge, MA: MIT Press.

van Eimeren, T., Monchi, O., Ballanger, B., and Strafella, A. P. (2009). Dysfunction of the default mode network in Parkinson disease: a functional magnetic resonance imaging study. Arch. Neurol. 66, 877-883. doi: 10.1001/archneurol. 2009.97

Voon, V., Mehta, A. R., and Harlett, M. (2011). Impulse control disorders in Parkinson's disease: recent advances. Curr. Opin. Neurol. 24, 324-330. doi: 10.1097/WCO.0b013e3283489687

Wolters, A. F., van de Weijer, S., Leentjens, A., Duits, A. A., Jacobs, H., and Kuijf, M. L. (2019). Resting-state fMRI in Parkinson's disease patients with cognitive impairment: a meta-analysis. Parkinsonism Relat. Disord. 62, 16-27. doi: 10.1016/j.parkreldis.2018.12.016

Yang, Z., Zheng, Y., Yang, G., Li, Q., and Liu, X. (2019). Neural signatures of cooperation enforcement and violation: a coordinate-based meta-analysis. Soc. Cogn. Affect. Neurosci. 14, 919-931. doi: 10.1093/scan/nsz073

Zinchenko, O. (2019). Brain responses to social punishment: a meta-analysis. Sci. Rep. 9:12800. doi: 10.1038/s41598-019-49239-1

Zinchenko, O., and Klucharev, V. (2017). Commentary: the emerging neuroscience of third-party punishment. Front. Hum. Neurosci. 11:512. doi: 10.3389/fnhum.2017.00512

Conflict of Interest: The authors declare that the research was conducted in the absence of any commercial or financial relationships that could be construed as a potential conflict of interest.

Copyright (C) 2020 Morese and Palermo. This is an open-access article distributed under the terms of the Creative Commons Attribution License (CC BY). The use, distribution or reproduction in other forums is permitted, provided the original author(s) and the copyright owner(s) are credited and that the original publication in this journal is cited, in accordance with accepted academic practice. No use, distribution or reproduction is permitted which does not comply with these terms. 